\title{
Severe hypercalcaemia in B-cell lymphoma: combined effects of PTH-rP, IL-6 and TNF
}

\author{
Anna Daroszewska, Roger C Bucknall, Patrick Chu, William D Fraser
}

\begin{abstract}
Summary
Hypercalcaemia as the only manifestation of B-cell lymphoma is seen very rarely. Its pathophysiology is heterogenous and not well understood. We report a 73-year-old man who presented with severe hypercalcaemia before any signs of malignancy became evident. He was diagnosed with a B-cell lymphoma on bone marrow trephine biopsy. The hypercalcaemia was associated with high plasma concentrations of parathyroid-hormone-related protein, interleukin-6 and tumour necrosis factor. Our patient had markedly increased osteoclast and osteoblast activity as a result of synergistic effects between these factors, with consequent severe hypercalcaemia. This is the first reported example of such combined effects of these factors in humans.
\end{abstract}

Keywords: hypercalcaemia; lymphoma; parathyroidhormone-related protein; tumour necrosis factor; interleukin-6

A 73-year-old Caucasian man was admitted to hospital with a 5-day history of lethargy, confusion, nausea, abdominal pain, and constipation. This was preceded by weight loss of about $6 \mathrm{~kg}$ over a 6 -week period. Previously he had been well, apart from benign colonic polyps kept under regular colonoscopy review and a recent chest infection that was treated. On admission he was dehydrated and confused, but had no other signs. Initial investigations revealed an adjusted calcium of 4.27 $\mathrm{mmol} / \mathrm{l}$ (normal range $2.2-2.6 \mathrm{mmol} / \mathrm{l}$ ), phosphate $1.76 \mathrm{mmol} / \mathrm{l}(0.70-1.40)$, urea 22.5 $\mathrm{mmol} / 1$ (2.5-7.0), creatinine $391 \mu \mathrm{mol} / 1$ (50130), alkaline phosphatase 241 IU/1 (35-125), erythrocyte sedimentation rate $40 \mathrm{~mm} / \mathrm{h}$, haemoglobin $11.4 \mathrm{~g} / \mathrm{dl}$, mean corpuscular volume $87 \mathrm{fl}$ (80-100), white cell count $11.3 \times$ $10^{9} / 1$ (neutrophils $9.6 \times 10^{9} / 1$, lymphocytes 0.6 $\times 10^{9} / 1$ ), platelets $407 \times 10^{9} / 1$. Chest X-ray was normal. He was treated with $0.9 \%$ saline intravenously and although his condition improved (calcium concentration returned to within reference range after 2 weeks and kidney function after 5 weeks), alkaline phosphatase of bony origin (confirmed by electrophoresis) increased to $777 \mathrm{IU} / 1$ on day 8 raising a strong possibility of bony metastases. Bone scintigraphy, however, did not reveal any localised increased activity but was suggestive of diffuse metabolic disease (there was prominent lung and kidney uptake due to microcalcification, but no evidence of neoplastic deposits). The prostatic specific antigen was normal and myeloma screen (serum and urine immunoelectrophoresis) was negative. Abdominal ultrasound was also normal. Screening investigations for metabolic causes of hypercalcaemia (thyroid-stimulating hormone/thyroxine, vitamin D, magnesium, angiotensin-converting enzyme concentrations, short synacthen test) were all normal or within reference range. Parathyroid hormone level was found to be low at $0.8 \mathrm{pmol} / 1$ (1.1-6.9). Colonoscopy confirmed the presence of benign polyps only.

On day 9 the patient developed pain in both knees. X-Rays revealed multifocal osteopenic peri-articular areas raising again the possibility of metastases or myeloma (figure). Similar abnormalities were later found throughout the radius and ulna of both arms. X-Rays of the skull and hands (apart from degenerative changes) were normal. Parathyroid hormone related protein (PTH-rP) was found to be elevated at $1.3 \mathrm{pmol} / 1$ (Diasorin, Stillwater,

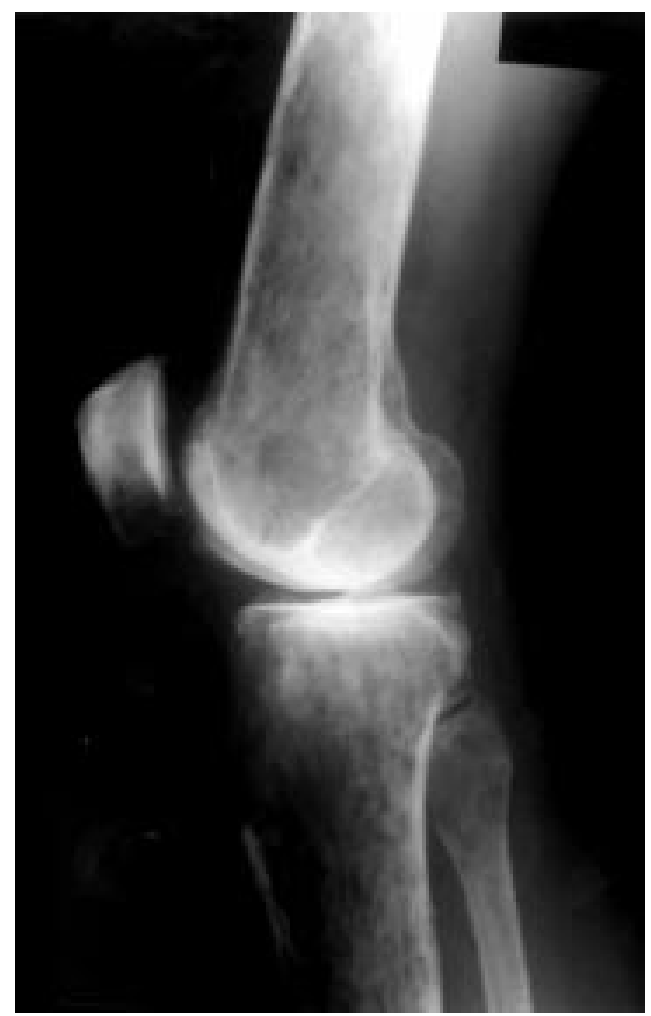

Figure X-Ray of patient's knee showing multifocal areas of peri-articular osteopenia 
USA) (reference range $<0.5 \mathrm{pmol} / 1$, established on 88 normal volunteers who were fit, healthy, ambulant subjects, normocalcaemic and not on medication affecting calcium metabolism; mean age 51 years, range 33-88). After 3 weeks in hospital hypercalcaemia recurred and disodium pamidronate intravenously with calcitonin subcutaneously were required as there was no response to saline diuresis only. Significantly elevated pyridinium crosslinks: urinary free pyridinoline (UfPyr)/creatinine 67.7 (5.0$21.8 \mathrm{nmol} / \mathrm{mmol}$ ), urinary free deoxypyridinoline (UfDPyr)/creatinine $21.5(0.4-6.4 \mathrm{nmol} /$ $\mathrm{mmol}$ ), and a UfPyr/UfDPyr ratio of 3.14 (3.3-5.2), confirmed very high bone resorption. Although computed tomography (CT) of brain, chest and abdomen was normal (the axial skeleton, apart from degenerative changes, appeared intact), CT review of both tibiae showed ill-defined lytic lesions suggestive of myeloma.

Bone marrow aspiration and trephine from the iliac crest was carried out. The aspirate was normal but the trephine biopsy showed lymphoid aggregates consistent with a diffuse large B-cell lymphoma, high grade (immunohistochemical profile: leucocyte common antigen positive, cytokeratin and prostate antigens negative, B-cell markers positive, T-cell markers negative). At that stage plasma tumour necrosis factor (TNF) was significantly elevated at $83.2 \mathrm{pg} / \mathrm{ml}(<15)$. Also, levels of interleukin-6 (IL-6) and C-reactive protein were increased at $20.7 \mathrm{pg} / \mathrm{ml}(<12)$ and $37 \mathrm{mg} / 1$ $(<5)$, respectively (table). The patient was treated with CHOP regime (cyclophosphamide, doxorubicin, vincristine, prednisolone) to which he responded well. His progress was complicated by a pathological fracture of left distal radius. After two courses of CHOP he was discharged home feeling well, with a view to further chemotherapy. His adjusted calcium concentration decreased gradually after the treatment with disodium pamidronate and cal-

Table Changes of C-reactive protein, IL-6, TNF, and calcium over time. Hypercalcaemia responded at first to rehydration, but later required disodium pamidronate and calcitonin. IL- 6 and TNF normalised after CHOP

\begin{tabular}{|c|c|c|c|c|}
\hline Day & $\begin{array}{l}C R P \\
(m g / l)\end{array}$ & $\begin{array}{l}I L-6 \\
(p g / m l)\end{array}$ & $\begin{array}{l}T N F \\
(p g / m l)\end{array}$ & $\begin{array}{l}\text { Adj } \mathrm{Ca}^{2+} \\
(\mathrm{mmol} / \mathrm{l})\end{array}$ \\
\hline $\begin{array}{l}\text { Normal range } \\
1\end{array}$ & $<5$ & $<12$ & $<15$ & $\begin{array}{l}2.2-2.6 \\
4.27\end{array}$ \\
\hline \multicolumn{5}{|l|}{$0.9 \%$ Saline } \\
\hline 10 & 14 & 14.0 & 39.8 & 2.79 \\
\hline 14 & & & & 2.50 \\
\hline 21 & & & & 2.95 \\
\hline 26 & 16 & 16.2 & 63.0 & 3.53 \\
\hline 31 & 27 & 19.6 & 65.4 & 3.71 \\
\hline \multicolumn{5}{|c|}{ Pamidronate and calcitonin } \\
\hline 32 & 22 & 14.7 & 72.9 & 3.51 \\
\hline 33 & 21 & 13.1 & 75.8 & \\
\hline 34 & 19 & 8.9 & 75.5 & 2.41 \\
\hline 35 & 18 & 11.2 & 76.5 & 2.30 \\
\hline 46 & 37 & 20.7 & 83.2 & 2.12 \\
\hline \multicolumn{5}{|l|}{ CHOP } \\
\hline 53 & 16 & 5.8 & 9.2 & 1.83 \\
\hline 59 & & & & 2.23 \\
\hline
\end{tabular}

Abbreviations: CRP = C-reactive protein, IL-6 = interleukin- 6 $\mathrm{TNF}=$ tumour necrosis factor, $\mathrm{Adj} \mathrm{Ca}^{2+}=$ calcium adjusted for albumin, $\mathrm{CHOP}=$ cyclophosphamide, doxorubicin, vincristine, prednisolone citonin to a nadir of $1.83 \mathrm{mmol} / \mathrm{l}$ and subsequently normalised.

\section{Discussion}

Hypercalcaemia is most commonly associated with primary hyperparathyroidism and malignancy. ${ }^{1}$ In haematological neoplasms it often occurs in the course of multiple myeloma (about 33\% of cases) and is nearly always associated with extensive osteolytic skeletal involvement. ${ }^{12}$ Only $1-2 \%$ of patients with lymphoma and leukaemia ${ }^{3}$ develop this complication (except with adult T-cell leukaemia in which it is common). In non-Hodgkin's lymphoma the finding of hypercalcaemia at presentation is extremely rare (less than $3 \%$ of cases), ${ }^{4}$ although in advanced disease with skeletal involvement the incidence may be as high as $34 \% .^{5}$ To the best of our knowledge, there has been only one case of isolated hypercalcaemia as the presenting feature of a B-cell lymphoma reported in the English literature up to now. ${ }^{6}$ In that case, hypercalcaemia was attributed to elevated PTH-rP.

The pathophysiology of hypercalcaemia in haematological malignancies may involve factors produced by the malignant cells: PTH-rP, TNF, IL-1, IL-6, and 1,25-dihydroxyvitamin $\mathrm{D}$, which stimulate osteoclast-mediated bone resorption. $^{7}$ In some cases, activated host immune cells may produce TNF or $\mathrm{IL}^{-1}{ }^{7}$ and in turn these cytokines can induce IL-6 production by T-cells. Most reports of hypercalcaemia associated with malignancy have identified single factors that are thought to cause the elevated calcium. Our patient is the first reported case of a malignancy resulting in high circulating plasma concentrations of three osteoclast-stimulating factors: TNF, PTH-rP and IL-6. Their production in combination may demonstrate synergism, resulting in the severe recurrent hypercalcaemia. Animal models have shown that such synergism occurs when TNF is combined with $\mathrm{PTH}^{\mathrm{T}} \mathrm{rP}^{8}$ or IL-6. ${ }^{9}$ This is thought to be due to an enhanced effect of two factors on production of early osteoclast precursors with subsequent increase in osteoclastic bone resorption. PTH-rP mediated bone resorption coupled with bone formation is increased two-fold by $\mathrm{TNF}^{8}$ In our patient, this potent combination of factors resulted in widespread skeletal effects with biochemical and radiological findings suggestive of multiple myeloma or disseminated carcinoma, but not lymphoma (although sclerotic lesions would have been expected in carcinoma and it would be unusual to find myeloma involving distal bones). Unlike myeloma, our patient had an elevation of bone alkaline phosphatase which increased three-fold following treatment of the hypercalcaemia, and also had generalised increased activity on bone scintigraphy, which reflected increased osteoblast activity, most probably secondary to the systemic effect of the combination of TNF and PTH-rP. It is also possible that the very high osteoclast activity was releasing a factor such as transforming growth factor $\beta$ (TGF $\beta$ ) which is a potent regulator of osteoblast activity. TGF $\beta$ 
is released in increased amounts by osteoclasts that are stimulated by factors such as PTH-rP in bone cultures. ${ }^{10}$

Despite bone marrow involvement and anaemia, the peripheral blood picture on presentation was relatively normal and a trephine bone marrow biopsy was required to establish the diagnosis. In hypercalcaemia of undetermined origin, haematological malignancies should be considered a possibility. The significant systemic effects may be due to production of a number of local and systemically active factors. This case casts a new light on the understanding of the complex pathophysiology that may arise in hypercalcaemia of malignancy.

\section{Learning points}

- in hypercalcaemia of undetermined origin, haematological malignancies should be considered a possibility and a bone marrow aspirate/trephine performed

- in B-cell lymphoma the tumour cell-bone micro-environment can result in the production of factors which can stimulate both osteoclasts and osteoblasts

- there is increasing evidence that the systemic synergism between PTH-rP, TNF and/or IL-6 results in significant osteoclast stimulation which may be responsible for hypercalcaemia of malignancy
1 Mundy GR, Martin TJ. The hypercalcaemia of malignancy: pathogenesis and management. Metabolism 1982;31:124777.

2 Mundy GR, Bertolini DR. Bone destruction and hypercalcaemia in plasma cell myeloma. Semin Oncol 1986;13:2919 .

3 Strewler GJ, Nissenson RA. Hypercalcaemia in malignancy. West f Med 1990;153:635-40.

4 Canellos GP. Hypercalcaemia in malignant lymphoma and Canellos GP. Hypercalcaemia in malignant ly

5 Moses AM, Spencer MH. Hypercalcaemia in patients with Moses AM, Spencer MH. Hypercalcaemia in patients
malignant lymphoma. Ann Intern Med 1963;59:531-6. 6 Ranganath L, Jamal H, Jones L, Goddard PF. Value of extreme hypercalcaemia. F Clin Pathol 1998;51:257-8.
7 Mundy GR. Incidence and pathophysiology of hypercalcaemia. Calcif Tissue Int 1990;46(suppl):S3-10.

8 Uy HL, Mundy GR, Boyce BF, et al. Tumour necrosis factor enhances parathyroid hormone-related protein-induced hypercalcaemia and bone resorption without inhibiting bone formation in vivo. Cancer Res 1997;57:3194-9.

9 De La Mata J, Uy HL, Guise TA, et al. Interleukin-6 enhances hypercalcaemia and bone resorption mediated by parathyroid hormone-related protein in vivo. 7 Clin Invest 1995; $95: 2846-52$.

10 Pfeilschifter J, Bonewald L, Mundy GR. Characterization of the latent transforming growth factor beta complex in bone. f Bone Miner Res 1990;5:49-58.

\title{
Verrucous carcinoma of the female breast
}

\author{
N A Munro, C Smith, A D Purushotham
}

\begin{abstract}
Summary
Verrucous carcinoma is a rare skin malignancy of squamous cell origin. It is characterised by negligible cellular atypia and a low mitotic rate. These are reflected in slow locally invasive behaviour and very infrequent metastatic spread. The tumour is also recognised in oral and anogenital sites. Cutaneous lesions present most commonly on the sole of the foot. We report a unique case occurring in the female breast.
\end{abstract}

Keywords: verrucous carcinoma; breast

A 75-year-old woman presented at the breast clinic with an alleged one-year history of an enlarging lesion of her right breast. On examination, the lateral aspect of the breast was replaced by an exophytic and superficially necrotic lesion measuring $120 \times 110 \mathrm{~mm}$ (figure 1). This was thought clinically to represent advanced breast carcinoma. Two incisional biopsies were taken on separate occasions under local anaesthesia, however, and the lesion was pathologically reported as a benign viral wart. The patient proceeded to wide local excision of the lesion, and frozen section examination at the time of operation was reported as a well-differentiated benign squamous lesion. Examination of paraffin sections from this specimen (figure 2) revealed an acanthotic and hyperkeratotic lesion with both endophytic and exophytic components. There was minimal nuclear pleomorphism and mitoses were confined to the basal layers. The appearances were typical of a verrucous carcinoma, and immunocytochemistry was positive for human papilloma virus. Local excision of the lesion was complete, and the patient made a good clinical recovery. She remains well on follow-up. 


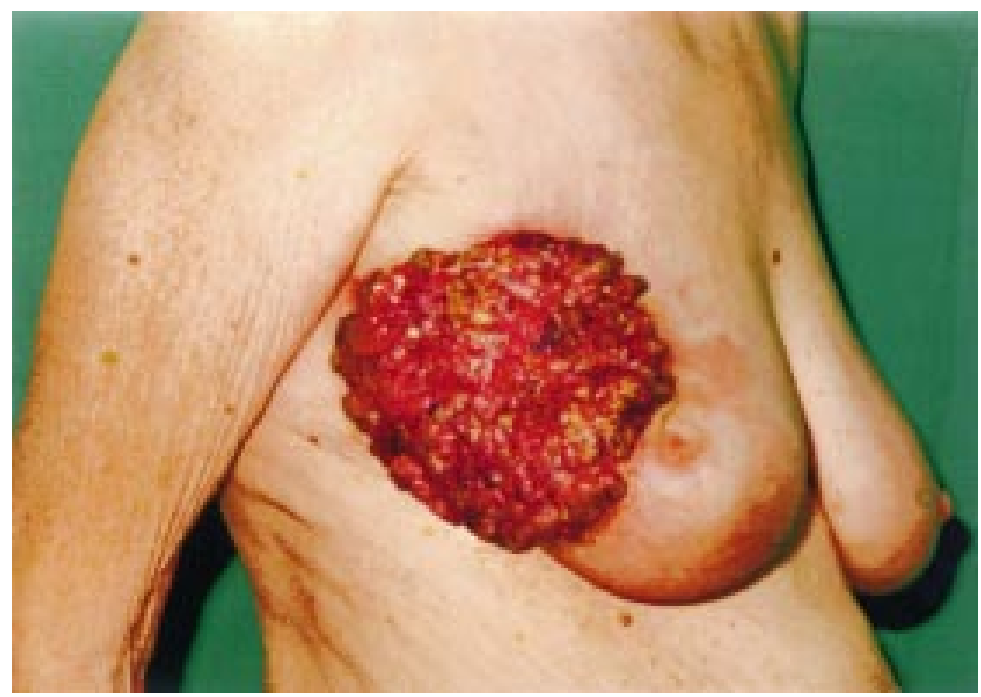

Figure 1 Pre-operative photograph showing exophytic lesion of right breast (reproduced with the patient's permission)

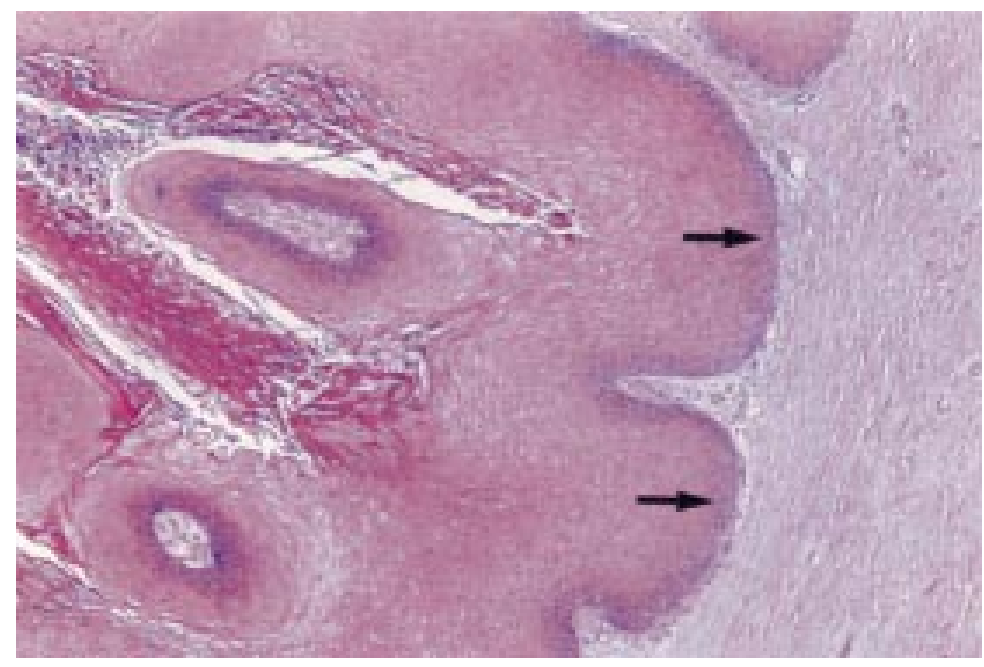

Figure 2 Photomicrograph of lesion showing well differentiated squamous architecture and deep pushing margin indicated by arrows (Haematoxylin and eosin stain, original magnification $\times 10$ )

\section{Learning points}

- verrucous carcinoma is a discrete condition with behaviour intermediate between squamous papilloma and squamous cell carcinoma

- although verrucous carcinoma usually affects the oral cavity, anogenital area or foot, consideration must be given to the diagnosis in other anatomical areas

- diagnosis can be difficult even on histological examination

- histological confirmation of breast carcinoma, even in apparently clear-cut cases, is essential to prevent unnecessarily mutilating surgery

\section{Discussion}

Verrucous carcinoma is a well known but rare tumour which is distinct from both squamous papilloma and squamous cell carcinoma, and intermediate between them in its behaviour. ${ }^{1}$ Human papilloma virus infection has been implicated in the aetiology of both verrucous carcinoma and the viral wart, with subtypes 11 and 18 having been previously demonstrated in cutaneous lesions. ${ }^{2}$ Verrucous carcinoma is difficult to diagnose on biopsy, due to the lack of cytological features of malignancy. Microscopic features are notoriously similar to those of a viral wart ${ }^{3}$ but, in a large biopsy or excisional specimen, it can be differentiated by its characteristic 'pushing' endophytic invasive margin (figure 2). To our knowledge, this is the first published case of verrucous carcinoma of the female breast. In view of its good prognosis, and the difficulty in reaching histological diagnosis on small biopsy samples, knowledge of this condition is useful in order to facilitate appropriate management.

3 Schwartz RA. Verrucous carcinoma of the skin and mucosa. f Am Acad Dermatol 1995;32:1-21.
1 Noel JC, Heenen M, Peny MO, et al. Proliferating cell nuclear antigen distribution in verrucous carcinoma of the skin. Br f Dermatol 1995;133:868-73.

2 Garven TC, Thelmo WL, Victor J, Pertschuk L. Verrucous carcinoma of the leg positive for human papillomavirus DNA 11 and 18: a case report. Hum Pathol 1991;22:1170- 


\title{
Eye disease in a patient with rheumatoid arthritis
}

\author{
M Shinzato, J Yamamoto, C E Hirata, A C Goldberg, N H Yoshinari, E Bonfá
}

\begin{abstract}
Summary
We report the case of a 40-year-old women with diffuse uveitis, sensorineural hearing loss and cerebrospinal fluid pleocytosis as features of Vogt-Koyanagi-Harada syndrome who developed symmetric polyarthritis and stiffness of small and large joints, in addition to rheumatoid arthritis. Although their target tissues are distinct, both diseases have a possible autoimmune origin strongly associated with HLADRB4.
\end{abstract}

Keywords: Vogt-Koyanagi-Harada syndrome; rheumatoid arthritis; autoimmune disease

Vogt-Koyanagi-Harada (VKH) syndrome is a multi-organ disorder affecting pigmented structures, such as the eye, inner ear and meninges. It can also affect skin. It has been described as an inflammatory condition of autoimmune nature in which cytotoxic $\mathrm{T}$ cells target the melanocytes. ${ }^{1}$ The strong association of $\mathrm{VKH}$ disease with DR4/DR53 in the Japanese population has been known since 1976 and has also been described in patients of Hispanic origin living in Southern California. In these patients, a secondary association to HLA-DR1 was also described, involving the share sequence linked to rheumatoid arthritis. ${ }^{2}$

Rheumatoid arthritis (RA) is a common chronic inflammatory disease characterised by a symmetric sterile and progressive synovitis within joints. Approximately $75 \%$ of patients with RA exhibit a positive rheumatoid factor. After several months or years from disease onset, characteristic bone erosions become apparent on X-rays. It is also associated with HLA-DR4 and DR1 alleles that share a sequence motif in the third hypervariable region, therefore named rheumatoid epitope. ${ }^{3}$ The most common ocular symptom in RA is keratoconjunctivitis sicca, occurring in $9-31 \%$ of patients. The frequency of scleritis is said to be $0.15-6.3 \% .{ }^{4}$ Episcleritis, scleromalacia perforans, and corneal ulceration may also be found. Uveitis is rare in adult RA.

In this paper we report a case of RA associated with VKH syndrome. To the best of our knowledge, such an association has only been described once before. ${ }^{5}$

\section{Case report}

Nineteen years ago, a white 40-year-old woman was admitted with a history of blurred vision, ocular discomfort, photophobia accompanied by headache, dizziness and hearing loss.
She also complained of arthralgias with morning stiffness. On initial examination, her visual acuity was hand movements at both eyes. She had $3+$ cells and $2+$ flare in both anterior chambers. There was $1+$ cells in both anterior vitreous bodies. A bilateral serous retinal detachment was present. Audiometric evaluation revealed sensorineural impairment of both ears. Cerebrospinal fluid (CSF) displayed 112 cells/dl, predominantly of lymphomononuclear origin (96\%); Wassermann and VDRL reactions were negative. Serology for toxoplasmosis was also negative. Haemoglobin level was 13.8 $\mathrm{g} / \mathrm{dl}$, and erythrocyte sedimentation rate (ESR) was $27 \mathrm{~mm}$ in the first hour. The patient was treated with prednisone $1 \mathrm{mg} / \mathrm{kg}$, and showed improvement of ocular disease as well as of the neurologic and otologic symptoms. Although the prednisone reduction was extremely gradual over a period of 10 years, the patient had several recurrences of the ocular manifestations with posterior development of bilateral cataract. Cataract surgery was performed in 1988. The eye diseases remained stable with low dose corticosteroid. Examination of the fundus shows the 'sunset glow' appearance (figure 1) typical of $\mathrm{VKH}$ syndrome.

Over the next 4 years, she developed polyarthritis of large and small joints with morning stiffness lasting for an hour. She presented poor motion and symmetric arthritis of wrists, metacarpophalangeal, proximal and distal interphalangeal joints, and also of the right knee and ankle. Laboratory tests disclosed hypochromic, normocytic anaemia (haemoglobin $10 \mathrm{~g} / \mathrm{dl}$ ). The ESR was $56 \mathrm{~mm}$ in the first hour. Her polyclonal gammaglobulin level was high

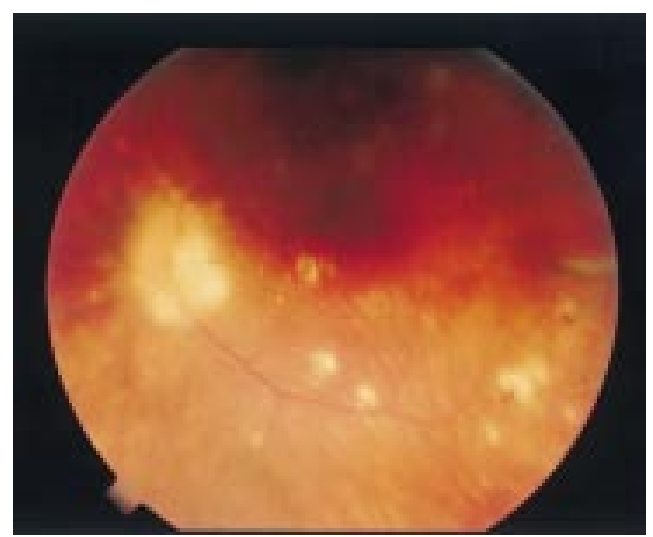

Figure 1 The 'sunset glow' appearance of the fundus and retinal pigment epithelium from resolved Dalen fuchs nodules in a convalescent phase of $\mathrm{VKH}$ syndrome 


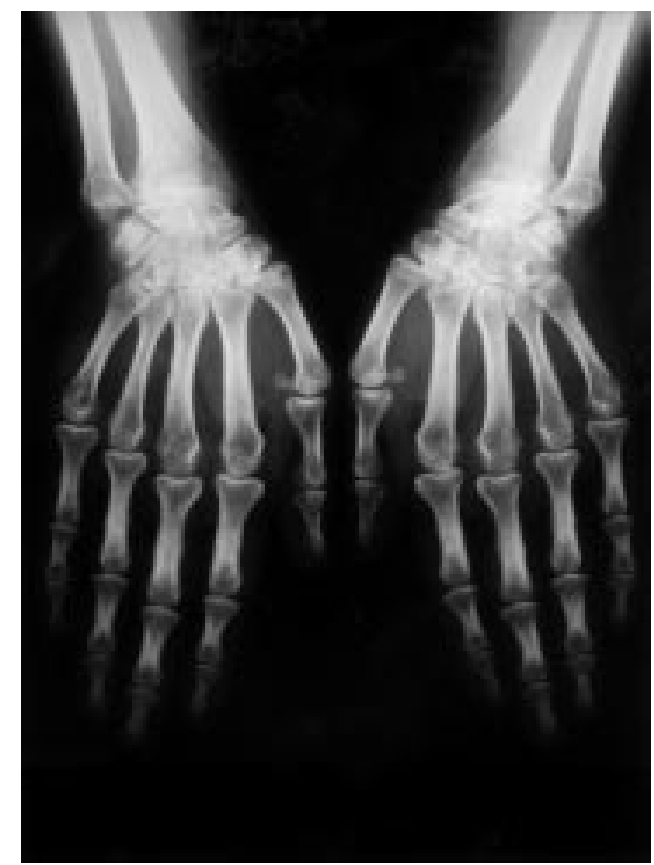

Figure 2 X-Ray of the patient's hands showing a symmetric peri-articular osteopenia, cartilage narrowing and bone erosions, especially in the wrists

on protein electrophoresis. Rheumatoid factor (RF) was positive. Her HLA class II profile was DR4 (DRB1*0401), DR11，DR52，DR53, DQ7, DQ8. Radiography of the patient's hands (figure 2) shows peri-articular osteopenia, cartilage narrowing and bone erosions, especially in the wrists.

\section{Discussion}

The exudative retinal detachment panuveitis without a history of eye trauma associated with pleocytosis of CSF and sensorineural impairment of ears confirmed the diagnosis of

1 Moorty, RS, Inomata, H, Rao, NA. Vogt-Koyanagi-Harada syndrome. Surv Ophthalmol 1995; 39: 265-92.

2 Weiz, JM, Holland, GN, Roer LN, et al. Association between Vogt-Koyanagi-Harada syndrome and HLA-DR1 and DR4 in Hispanic patients living in southern California. Ophthalmology 1995;102:11012-5.

3 Gregerson, PK, Silver, J, Winchester, RJ. The share epitope hypothesis: an approach to understanding the molecular genetics of susceptibility to rheumatoid arthritis. Arthritis Rheum 1987;30:1205-13.

4 Matsuo T, Kono R, Matsuo N, et al. Incidence of ocular complications in rheumatoid arthritis and the relation of keratoconjuntivitis sicca with its systemic activity. Scand $f$ Rheumatol 1997;26:113-6.

5 Egashira K, Yamamoto T, Tsuji S, Onishi A, Muray Y. A case of myastenia gravis complicated with chronic rheumatoid arthritis and Vogt-Koyanagi-Harada disease. Rinsho Shinkeigaku 1987;27:859-61.

\section{Learning points}

- rheumatoid arthritis and Vogt-Koyanagi-Harada syndrome can occur concomitantly

- they are both supposed to have an autoimmune nature

- although they are both associated with HLA-DR4, they have different target tissues

Vogt-Koyanagi-Harada syndrome according to the criteria established by the American Uveitis Society. ${ }^{6}$ Dermatological findings described in $\mathrm{VKH}$ are alopecia, poliosis and vitiligo, but our patient did not have any of these cutaneous manifestations. On the other hand, she presented with arthralgia and morning stiffness which have not been described in this disease. In fact, later, this patient developed a symmetric erosive polyarthritis, including an elevated ESR and positivity to rheumatoid factor fulfilling the American Rheumatism Association criteria for RA. ${ }^{7}$ The finding of HLA-DRB $1{ }^{\star} 0401$ further supports this diagnosis.

The aetiology of VKH is unknown but its autoimmune nature is suggested by the occasional association with disease such as polyglandular syndrome type $\mathrm{I}^{8}$ and scleroderma. ${ }^{9}$ The association presented herein is particularly interesting since the two conditions are associated with HLA-DR4 alleles which share the sequence linked to RA. Although the most common allele in $\mathrm{VKH}$ is $\mathrm{DRB} 1^{\star} 0405$, pocket 4 is very similar in $\mathrm{DRB} 1{ }^{\star} 0401$ and 0405 and outlines the peptide-binding motif for RA. ${ }^{10}$

In conclusion, this report describes a rare case of RA-associated VKH syndrome. Although the real occurrence of $\mathrm{VKH}$ among the RA population is unknown because of the rarity of the former, this report presents an opportunity to establish an eventual relationship between these two diseases of autoimmune origin.

6 Snyder DA, Tessler HH. Vogt-Koyanagi-Harada syndrome. Am f Ophthalmol 1980;90:69-71.

7 Arnett FC, Edworthy SM, Block DA. The American Rheumatism Association 1987 revised criteria for the classification of rheumatoid arthritis. Arthritis Rheum 1988;31: $558-9$.

8 Jovic NS, Nesovic M, Vransevic DN, Ciric J, Marincovic DM, Bonaci B. The Vogt-Koyanagi-Harada syndrome association with autoimmune polyglandular syndrome type association with autoimmune polyg

9 Cavalli C, Gobbi PG, Colombo R, Ricardi A, Gorini M, Ascari E. Un cas de sclérodermique et association au syndrome de Vogt-Koyanagi-Harada. Presse Méd 1985;14: $1131-4$

10 Hammer J, Gallazi F, Bono E, et al. Peptide-binding specificity of HLA-DR4 molecules: correlation with rheumatoid arthritis association. $\mathcal{F}$ Exp Med 1995;181:1847-55. 


\title{
Ciguatera fish poisoning
}

\author{
John A Crump, Colin L McLay, Stephen T Chambers
}

\begin{abstract}
Summary
Ciguatera fish poisoning is one of a variety of non-bacterial forms of human seafood poisoning. Consuming large predatory fish from tropical reef ecosystems may be hazardous. We describe a case that is typical of the disease, and illustrates the persistence of neurological symptoms that occur in some patients.
\end{abstract}

Keywords: ciguatera fish poisoning; ichthyosarcotoxaemia; poisoning; biotoxins

Department of

Infectious Diseases,

Christchurch Hospital,

Private Bag 4710,

Christchurch, New

Zealand

J A Crump

S T Chambers

\section{Department of}

Zoology, University of

Canterbury, Private

Bag 4800,

Christchurch, New

Zealand

C L McLay

Correspondence to Dr John A Crump, Fellow,

Department of Clinical

Microbiology, Duke

University Medical Center

Box 3879, Durham, NC

27710, USA

Accepted 13 May 1999
Humans who eat large predatory reef fish in the tropics risk the acute and sometimes severe neurological and gastrointestinal symptoms associated with ciguatera fish poisoning. Acute management is symptomatic and supportive. Intravenous mannitol may be of use. Sequelae include chronic dysesthesia, which may be relieved by amitriptyline.

Ciguatoxin is a lipid-soluble polyether compound $^{1}$ that is probably synthesised by specific bacteria after phagocytosis by the benthic dinoflagellate Gambierdiscus toxicus (figure 1). The organism adheres to dead coral surfaces and bottom-associated algae. The toxin is then concentrated in the food web as the dinoflagellates are eaten by herbivorous fish species that graze on algae and detritus. These fish are in turn eaten by the larger marine carnivores, which may then be eaten by humans. As the toxin concentration is elevated along the food chain, larger fish are likely to contain

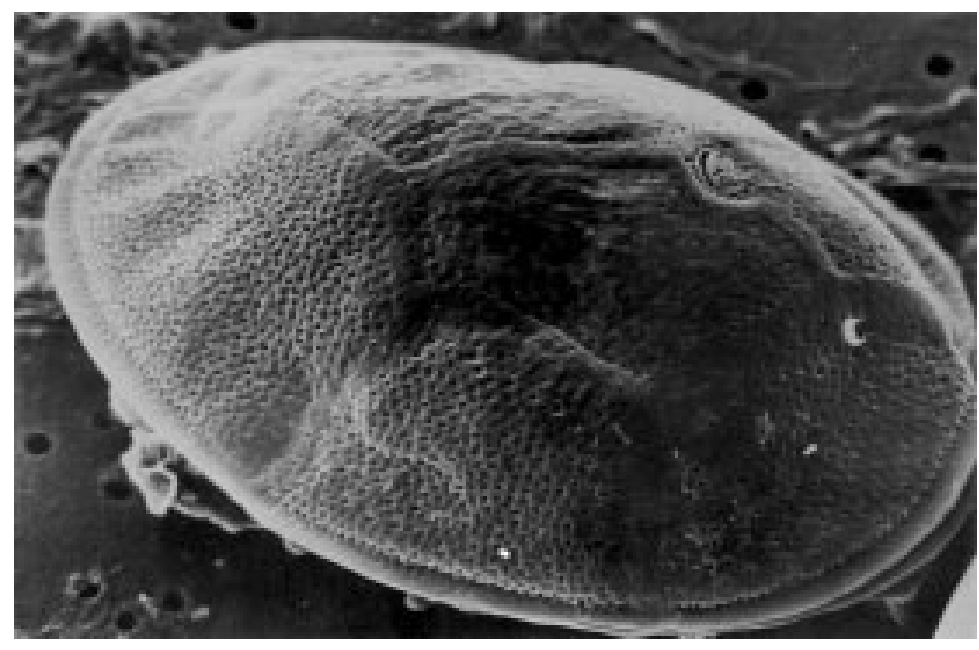

Figure 1 Electron micrograph of the benthic dinoflagellate Gambierdiscus toxicus. Actual diameter $60 \mu \mathrm{m}$. Reproduced with permission of CSIRO, Australia from Hallegraeff ${ }^{11}$ larger concentrations of toxin. We present a case illustrating the acute and chronic manifestations of ciguatera fish poisoning in humans.

\section{Case report}

A 42-year-old man presented 3 weeks after returning from Fiji complaining of insomnia, lethargy, dysesthesia of hands and feet, occasional cramps in the calves, light-headedness on standing, and a dry mouth. While in Fiji he had eaten barbecued fish, and fed the remains to a local cat. Within three hours of eating the fish, he developed abdominal pain, watery diarrhoea, and developed a burning sensation of the skin overnight that became very severe the next day while swimming. $\mathrm{He}$ then developed increasing shortness of breath and noticed that the cat that ate the fish remains had died. The patient summoned the help of a local who viewed the fish remains, and noted them to be of a species commonly associated with fish poisoning, and suggested he go immediately to hospital. On arrival he was in marked respiratory distress, weak, and experiencing cramps. He required a period of respiratory supportive therapy. The following day he was maintaining adequate oxygenation without support, and was discharged. $\mathrm{He}$ returned to his home country. A diagnosis of ichthyosarcotoxaemia, clinically consistent with ciguatera fish poisoning, was made. Dysesthesia of the hands and feet persisted for weeks, but resolved after 5 days on amitriptyline $100 \mathrm{mg}$ daily.

\section{Discussion}

Ciguatera fish poisoning can occur in any region where humans eat carnivorous, and occasionally herbivorous, fish derived from tropical reef ecosystems. The toxin is unaffected by cooking, and no protective immunity is conferred by past exposure. In Fiji, Lutjanus spp, the Red Snapper or Red Bass (figure 2), and Plectropomus spp complex, the Coral Trout, are commonly implicated. The patient identified the Red Snapper as similar in colour and morphology to the fish he had eaten. Species which have been associated with ciguatera poisoning derive from the families Serranidae (groupers), Lutjanidae (snappers), Scaridae (parrot fish), Scombridae (mackerel), Muraenidae (moray eels), Sphyraenidae (barracudas), and Carangidae (jacks). Generally the disease occurs in a circumglobal belt between approximately $35^{\circ}$ north and $35^{\circ}$ south latitude, and is endemic in the tropical Indo- 


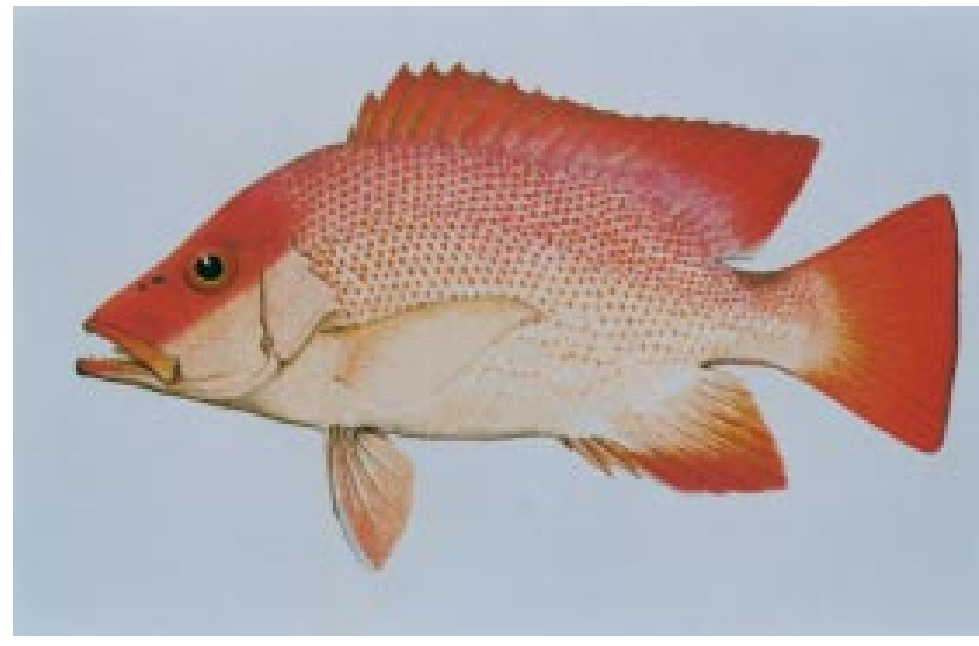

Figure 2 An example of Lutjanus spp, the Red Snapper or Red Bass. Reproduced with permission of HarperCollins Publishers, Australia, from Marshall ${ }^{12}$

Pacific Islands, and the Caribbean. Surveillance data suggests that incidence rates may be as high as 50 to 500 per 10000 population per year ${ }^{2}$ in the South Pacific region. The mortality rate is probably low with $0.1 \%$ being reported from a series from New Caledonia.

The mechanism of ciguatoxin-mediated disease in humans remains unclear. Suggested mechanisms include the 'opening' of sodium channels in cell membranes through the occupation of calcium sites, and both cholinergic and anticholinergic activity have been noted. ${ }^{4}$ The symptoms of ciguatera poisoning are well described, ${ }^{4}$ and include diarrhoea, vomiting, nausea, abdominal pain or cramping, bradycardia, hypotension, tachycardia, arthralgias, myalgias, paraesthesias of extremities, circumoral or facial paraesthesias, temperature reversal, asthenia, headache, pruritis, paresis, diaphoresis, dizziness or vertigo, ataxia, dyspnoea, and cough. As in our case, some symptoms may take weeks or months to resolve. ${ }^{5}$ The diagnosis is usually a clinical one, although it may now be supported by applying a rapid stick-enzyme immunoassay of horseradish and peroxidaselabelled sheep anti-ciguatera toxin antibody to the implicated fish.

Acute management is primarily supportive. Symptoms may be accentuated by the ingestion of alcohol. There is no available antitoxin. Anti-emetics, antidiarrhoeals, and intravenous rehydration are often necessary. Atropine has

1 Scheuer PJ, Takahashi W, Tsutsumi J, Yoshida T. Ciguatoxin: isolation and chemical nature. Science 1967;155:1267-8

2 Lewis ND. Disease and development: ciguatera fish poisoning. Soc Sci Med 1986;23:983-93.

3 Bagnis R, Kuberski T, Laugier S. Clinical observations on 3009 cases of ciguatera (fish poisoning) in the South Pacific. Am f Trop Med Hyg 1979;28:1067-73.

4 Barton ED, Tanner P, Turchen SG, Tunget CL, Manoguerra A, Clark RF. Ciguatera fish poisoning. A Southern California epidemic. West $\mathcal{F}$ Med 1995;163:31-5.

5 Pearn JH. Chronic fatigue syndrome: chronic ciguatera poisoning as a differential diagnosis. Med f Aust 1997;166:30910.

6 Auerbach PS. Ciguatera toxin poisoning. West f Med 1985; 142:380-1.

\section{Learning points}

- ciguatoxin is synthesised by bacteria phagocytosed by the benthic dinoflagellate Gambierdiscus toxicus

- ciguatoxin concentrates in the food web, reaching particularly high levels in large predatory reef fish

been used for treatment of symptomatic bradycardia. ${ }^{6}$ Intravenous calcium gluconate may have some theoretic benefit in counteracting the inhibition of calcium uptake by excitable membranes. ${ }^{7}$ Pralidoxime chloride has been used as a cholinesterase reactivator based on laboratory data that suggests that ciguatera toxin acts as a cholinesterase inhibitor, although a controlled trial has not been carried out. ${ }^{7}$ Amitriptyline has been shown to provide variable relief from the neurological symptoms associated with ciguatera poisoning, perhaps by membrane stabilisation via sodium channel blockade, or through its anticholinergic activity. ${ }^{8}$ An uncontrolled study using intravenous mannitol 0.5 to $1.0 \mathrm{~g} / \mathrm{kg}$ in a $20 \%$ solution given over 10 to 30 minutes produced immediate resolution of symptoms in most of 24 patients so treated. ${ }^{9}$ The mechanism of action is unclear, but may be related to membrane stabilisation.

Ciguatera fish poisoning is one of a variety of non-bacterial forms of seafood poisoning in humans. Others include paralytic, diarrhoetic, and amnesic shellfish poisoning, all of which are derived from dinoflagellate blooms, puffer fish poisoning due to tetrodotoxin, and clupeotoxism, ${ }^{10}$ which is also common in Fiji. Ciguatera fish poisoning may represent an under-reported and under-recognised cause of morbidity amongst travellers. Practitioners should consider including this health hazard amongst topics discussed with travellers prior to departure overseas. Tourists at greatest risk include those going on fishing tours, especially if they are not accompanied by an experienced local guide. Travellers should be warned of the risk and advised to avoid eating large predatory reef fish from tropical waters.

I would like to thank Mr Raymond Morse for kindly reviewing his own experience of ciguatera poisoning, and examining fish atlases to identify the likely offending species.

7 Morris JG Jr, Lewin P, Hargrett NT, Smith CW, Blake PA, Schneider R. Clinical features of ciguatera fish poisoning; a study of the disease in the US Virgin Islands. Arch Intern Med 1982;142:1090-2.

8 Bowman PB. Amitriptyline and ciguatera. Med F Aust 1984; $140: 802$

9 Palafox NA, Jain LG, Pinano AZ, Gulick TM, Williams RK, Schatz IJ. Successful treatment of ciguatera fish poisoning with intravenous mannitol. $\mathcal{F A M A} 1988 ; 259: 2740-2$.

10 Narayan Y. Fish poisoning in Fiji. Fiji Med 1980;8:567-74.

11 Hallegraeff GM. Plankton: a microscopic world. Australia: CSIRO, 1988.

12 Marshall TC. Fishes of the Great Barrier Reef and coastal waters of Queensland. Sydney: Angus \& Robertson Ltd, 1964. 


\title{
Concordance of primary generalised epilepsy and carbamazepine hypersensitivity in monozygotic twins
}

\author{
S G M Edwards, V Hubbard, S Aylett, D Wren
}

\begin{abstract}
Summary
In this paper we describe the previously unreported phenomenon of a carbamazepine-induced mucocutaneous syndrome in identical twins. These twins had developed primary generalised epilepsy within 2 months of each other.
\end{abstract}

Keywords: carbamazepine; hypersensitivity; twins; epilepsy

Treatment with anticonvulsant medication can be complicated by severe delayed hypersensitivity reactions. It has been proposed that the metabolism of aromatic anticonvulsants (phenytoin and carbamazepine) to toxic arene oxide metabolites may be involved. ${ }^{1}$ Familial clustering suggests the existence of a genetic predisposition to hypersensitivity reactions to phenytoin. ${ }^{2}$ There have been no previous reports of twins developing hypersensitivity reactions to any of the anticonvulsant drugs. Family and twin studies in epilepsy have been more extensive. Within affected sibships, the frequency of concordance for epilepsy in nontwin siblings is $12 \%$, similar to the frequency in co-twins of dizygotic probands ( $9 \%)$, but this is much less than the frequency in co-twins of monozygotic probands $(38 \%){ }^{3}$ This presumably reflects a major genetic component to certain epilepsies.

We describe a pair of identical twins that both developed primary generalised epilepsy and a carbamazepine-induced drug eruption within 2 months of each other.

Department of Clinica Neurology, St Mary's Hospital, Praed Street, Paddington, London W2 1NY, UK

S G M Edwards

V Hubbard

Neurosciences

Department, Great Ormond Street for Children NHS Trust and the Institute of Child Health (UCL

London), UK

S Aylett

Department of Clinical Neurology, Atkinson Morley's Hospital, Copse Hill London, UK D Wren

Accepted 17 May 1999

\section{Case report}

A 16-year-old man presented with two generalised tonic-clonic seizures without aura over a period of 2 months, for which he had been commenced on carbamazepine. He was one of a twin pair born by elective Caesarean section at 34 weeks gestation, both having identical birth weights of $2.3 \mathrm{~kg}$. Neither twin had a history of neonatal problems or febrile convulsions, and there was no family history of epilepsy. Physical examination of the patient was normal. Computed tomography of the brain was normal and electroencephalogram (EEG) showed mild changes with one episode of generalised sharpened forms. A diagnosis of primary generalised epilepsy was made. Ten weeks after treatment had been started he developed soreness of the mouth and lips, and on examination was found to have angular kelitis, ulceration of the lips and buccal mucosa, conjunctival injection, and a diffuse erythematous macular rash over the limbs and trunk and face (see figures).

Blood tests, including a full blood count and liver function tests, were normal, and mild mucocutaneous drug eruption was diagnosed. Carbamazepine was withdrawn and replaced by sodium valproate, with hydrocortisone ointment and antibacterial mouthwash also prescribed. Over the next few weeks the mucocutaneous inflammation settled and the patient remained seizure free.

The twin brother of this patient was also seen at the age of 16, once again with two generalised tonic-clonic seizure without aura 2 months apart, which came on 2 months after his brother's seizures. EEG was abnormal with some generalised epileptiform discharges consistent with primary generalised epilepsy. $\mathrm{He}$

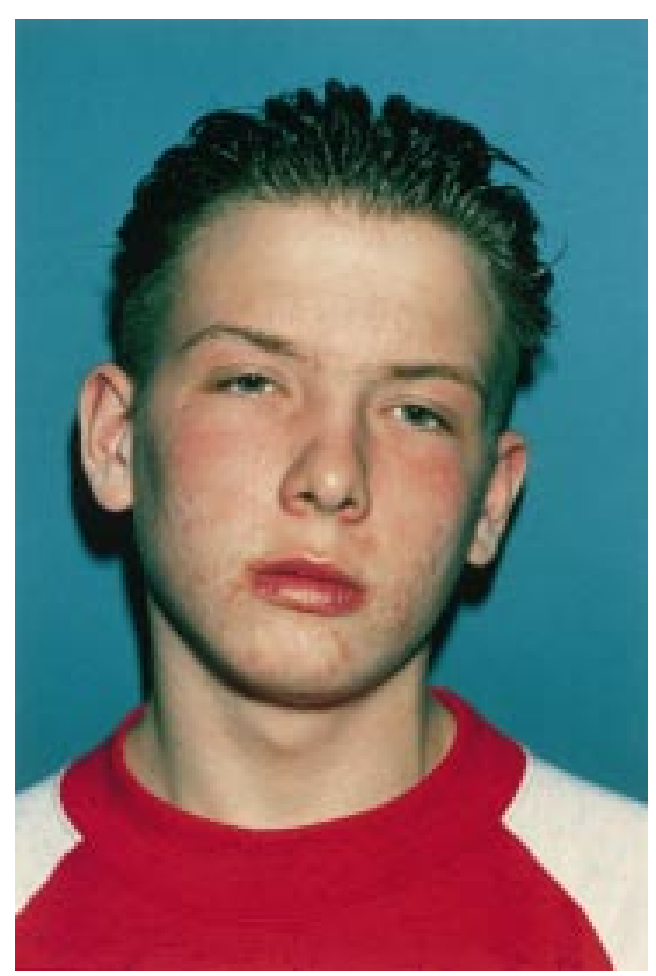

Figure 1 First twin, with generalised erythematous rash (reproduced with his permission) 


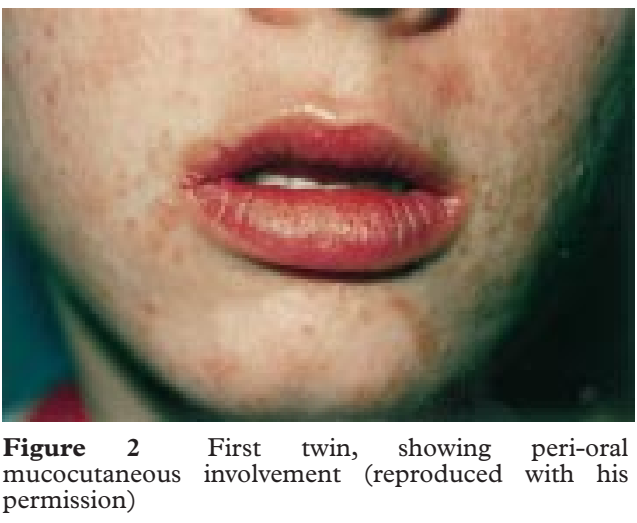

had also been commenced on carbamazepine, but after 4 weeks his mother stopped it having noticed similar mucocutaneous changes involving his skin and peri-oral region. The skin reaction settled and good epileptic control has since been maintained on sodium valproate.

The mother thought that the twins were identical, and genomic fingerprint testing revealed a probability of 1023 out of 1024 that they were monozygotic.

\section{Discussion}

Dose-independent effects of carbamazepine are often severe and include blood dyscrasias, hepatotoxicity, renal disorders and skin reactions. The dermatological sequelae have been reported to occur in $3-4 \%$ of patients and are usually mild rashes only. ${ }^{4}$ It has been reported that abnormal detoxification of reactive, electrophilic, metabolites may be the common

1 Shear NH, Spielberg SP, Cannon M, Miller M. Anticonvulsant hypersensitivity syndrome: in vitro risk assessment. $\mathcal{F}$ Clin Invest 1988;82:1826-32.

2 Gennis MA, Vemuri R, Burns EA, Hill JV, Miller MA Spielberg SP. Familial occurrence of hypersensitivity to phenytoin. Am $\mathcal{F}$ Med 1991;91:631-4.

\section{Learning point}

Delayed hypersensitivity is a severe potential side-effect of many medications. If one

monozygotic twin develops this reaction to a particular medication, serious consideration should be given before it is commenced in the other twin.

pathway for hypersensitivity reactions in the aromatic convulsants carbamazepine, phenytoin and phenobarbitone. ${ }^{1}$

Drug-induced mucocutaneous syndrome in twins has not previously been reported for any medication. The similarity in concordance in our patients for onset of epilepsy and reaction to carbamazepine is noteworthy. Both primary generalised epilepsy and drug-induced hypersensitivity reactions are likely to be multifactorial, with a significant genetic (presumably polygenic) as well as environmental component. The presence of similar mucocutaneous reaction to carbamazepine in these identical twins, supports the evidence for a genetic component to anticonvulsant hypersensitivity, which may act via abnormal detoxification of reactive metabolites. ${ }^{2}$

In monozygotic twin pairs in which one of the probands suffers a delayed hypersensitivity reaction to a particular medication, careful consideration should be given to commencing the same drug in the second twin, especially if the drugs belong to the same 'family' of medications, such as the aromatic anticonvulsants.

3 Berkovic SF, Howell RA, Hay DA, Hopper JL. Twin birth is not a risk factor for seizures. Neurology 1993;43:2515-9.

4 Ashmark $\mathrm{H}$, Wilholm $\mathrm{B}$. Epidemiology of adverse reactions to carbamazepine as seen in a spontaneous reporting system. Acta Neurol Scand 1990;81:131-40. 